\title{
Sleep Study Interpretation in Obstructive Sleep Apnea
}

\author{
Pralhad Prabhudesai ${ }^{1}$, Milan Patankar ${ }^{2}$, Anand Vardhan ${ }^{3}$
}

International Journal of Head and Neck Surgery (2019): 10.5005/jp-journals-10001-1369

\section{INTRODUCTION}

Sleep study or polysomnography (PSG) is a detailed analysis of sleep quality. Limited channel study where EEGs are not measured is called sleep polygraphy. Patient is supposed to sleep in a conducive environment and different electrodes are attached by a skilled sleep technician all over the body. The signals captured are then recorded throughout the night. At the end, a detailed report is ready to be analyzed by a sleep physician. Sleep study results should be interpreted carefully in light of indication for sleep study, level of study and cutoffs of variables corroborating well with the international standards. Usual indications for sleep study are snoring, excessive daytime sleepiness and easy fatigability. Additionally, other important indications have been uncontrolled hypertension or diabetes mellitus, nocturnal angina, unexplained polycythemia, poorly controlled obstructive airway diseases like COPD and bronchial asthma, recurrent heart failure, nocturnal arrhythmia, etc. All these patients can reach ENT outpatient department as well.

Sleep study can either be done as a full night study or split night study. Full night study means where diagnostic sleep study and CPAP titration are done on two separate nights. Split night study means where diagnostic study is performed in initial first half of the night showing evident apneas and hypopneas. Thereafter, in second half of same night CPAP titration is done. As per AASM recommendations, split night study should be preferred over whole night study if clinically acceptable, i.e. if certain criteria are met. In first half of the study period, a moderate to severe degree of OSA
1,3 Department of Respiratory Diseases, Lilavati Hospital and Research Centre, Mumbai, Maharashtra, India

${ }^{2}$ Department of Respiratory Diseases, Dhanwantri Hospital and Research Centre, Mumbai, Maharashtra, India

Corresponding Author: Pralhad Prabhudesai, Department of Respiratory Diseases, Lilavati Hospital and Research Centre, Mumbai, Maharashtra, India, email: aumclinic@gmail.com

How to cite this article: Prabhudesai P, Patankar M, Vardhan A. Sleep Study Interpretation in Obstructive Sleep Apnea. Int J Head Neck Surg 2019;10(2):42-46.

Source of support: Nil

Conflict of interest: None

should be observed during a minimum of 2 hours of recording time and at least 3 hours should be available for CPAP titration. The rationale for preference for split night study has largely been convenience for patient and cost effectiveness. However, any of the inconclusive portions like initial diagnostic part or CPAP titration, would warrant a repeat PSG. Also, split night study is best avoided if patient is suffering from severe insomnia or is a suspect for other forms of SDB.

There are 4 different levels of PSG as depicted in Table 1. Decision on level of study should depend upon symptomatology of patient, accompanying comorbid states and facilities available. One should always prefer level 1 study especially in patients with significant cardiorespiratory diseases, suspected restless leg syndrome,

Table 1: Level of sleep study

\begin{tabular}{|c|c|c|c|}
\hline Level of study & Setup & Parameters monitored & Remarks \\
\hline I & $\begin{array}{l}\text { Laboratory based, } \\
\text { supervised }\end{array}$ & $\begin{array}{l}\mathrm{EEG}, \mathrm{EOG} \text {, chin } \mathrm{EMG}, \mathrm{ECG} \text {, bilateral anterior tibialis } \\
\text { muscle activity, } \mathrm{SpO}_{2} \text {, sounds, respiratory thoracoab- } \\
\text { dominal movements } \\
\text { Additionally, transcutaneous } \mathrm{CO}_{2} \text {, digital video, es- } \\
\text { ophageal pressures can also be attached } \\
\text { "Gold standard" }\end{array}$ & $\begin{array}{l}\text { - Identifies sleep stages } \\
\text { - Quantifies respiratory events } \\
\text { - Distinguishes obstructive vs central } \\
\text { events } \\
\text { - Body position impact } \\
\text { - Can detect other sleep disorders }\end{array}$ \\
\hline II & $\begin{array}{l}\text { Portable, not super- } \\
\text { vised }\end{array}$ & $\begin{array}{l}\text { At least } 7 \text { variables monitored } \\
\text { EEG, EOG, chin EMG, ECG or heart rate, airflow, respira- } \\
\text { tory effort and oxygen saturation. }\end{array}$ & $\begin{array}{l}\text { Measures sleep stages } \\
\text { Should not be done with neuropsychologi- } \\
\text { cal issues or where video confirmation is } \\
\text { needed }\end{array}$ \\
\hline III & $\begin{array}{l}\text { Limited channel } \\
\text { study, not supervised }\end{array}$ & $\begin{array}{l}\text { At least } 4 \text { variables monitored } \\
\mathrm{SpO}_{2} \text {, respiratory effort, airflow, body position, EMG, } \\
\mathrm{ECG} \text {, actigraphy }\end{array}$ & $\begin{array}{l}\text { Should not be done in patients with low } \\
\text { pre test possibility and those with other } \\
\text { sleep disorders or evident comorbid states }\end{array}$ \\
\hline IV & $\begin{array}{l}\text { Limited channel, not } \\
\text { supervised }\end{array}$ & $\begin{array}{l}\text { Only } 1 \text { or } 2 \text { variables monitored oxygen saturation, } \\
\text { heart rate or airflow }\end{array}$ & $\begin{array}{l}\text { Should not be done in patients with low } \\
\text { pre test possibility and those with other } \\
\text { sleep disorders or evident comorbid states }\end{array}$ \\
\hline
\end{tabular}

ECG, electrocardiogram; EOG, electroocculogram; EMG, electromyogram; EEG, electroencephalogram

(O) The Author(s). 2019 Open Access This article is distributed under the terms of the Creative Commons Attribution 4.0 International License (https://creativecommons. org/licenses/by-nc/4.0/), which permits unrestricted use, distribution, and non-commercial reproduction in any medium, provided you give appropriate credit to the original author(s) and the source, provide a link to the Creative Commons license, and indicate if changes were made. The Creative Commons Public Domain Dedication waiver (http://creativecommons.org/publicdomain/zero/1.0/) applies to the data made available in this article, unless otherwise stated. 


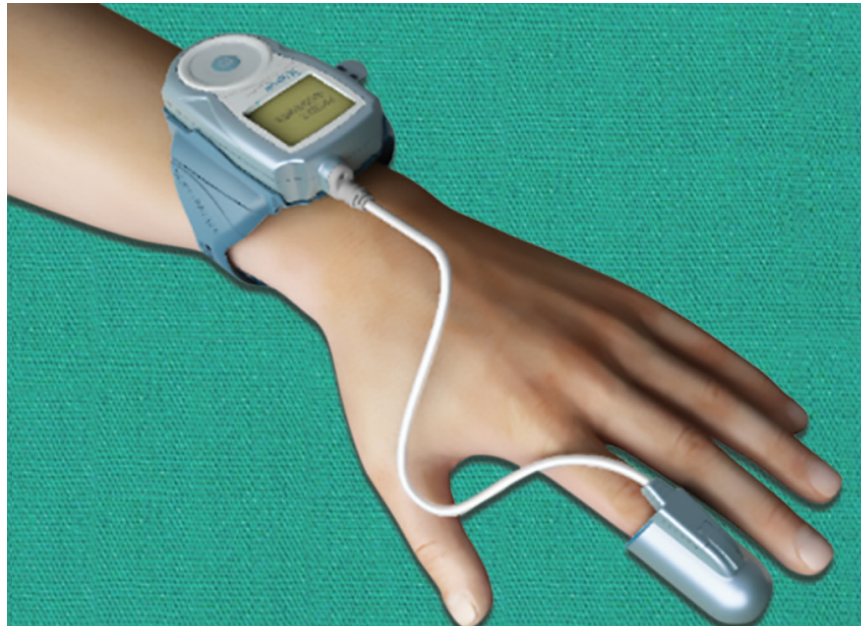

Fig. 1: Tool for HSAT measuring peripheral arterial tone

periodic limb movement, parasomnias, behavioral disorders, narcolepsy, bruxism, potential respiratory muscle weakness due to neuromuscular condition, awake hypoventilation or suspected sleep related hypoventilation, chronic opioid medication use, history of stroke or severe insomnia. If UARS is suspected, the sleep study level should be upgraded to level 1.

Home sleep apnea testing (HSAT) is another newly acceptable modality for sleep apnea testing though in specific scenario. It utilizes peripheral arterial tone, oxygen desaturation and changes in heart rate in analysing respiratory event. However, if a single HSAT is negative, inconclusive or technically inadequate, PSG is recommended (Fig. 1). ${ }^{2}$

\section{Prerequisite for Sleep Study Reporting}

- Thorough history and clinical examination is a must before interpretation of any sleep study report as mentioned in Sleep History Taking and Examination, Vol 10, Issue 1.

- Check the level of study as studies other than level I study have limitations

- Previous sleep study reports, if available should be checked

- It should be an acceptable PSG, ie. a minimum of 4 hours of adequate flow and oximetry tracing should be there.

- Remarks from sleep technician should be taken into consideration

- Ongoing drugs especially sleeping pills and intake of caffeine, nicotine or alcohol especially within 6 hours should be checked as they may interfere with sleep architecture and staging. However, if patient has been on a sleeping pill on long-term basis, they should be allowed to consume the same.

- Assessment of comorbid illnesses and the ongoing drugs should be screened

Sleep study results should be analyzed in detail by selecting an epoch of 10 seconds or 30 seconds, with selected parameters called montage. Different parameters are assessed by certain gadgets as mentioned in Figure 2 and Table 2.

Interpretation should ideally be done by a sleep physician who has sound knowledge to analyze the data as under diagnosis would project the patient to dreaded consequences of OSA and over diagnosis can give patient a huge financial burden in a developing country like ours. Understanding of certain terminologies mentioned on the report is imperative. This should be followed by analysis of respiratory or cardiac events.

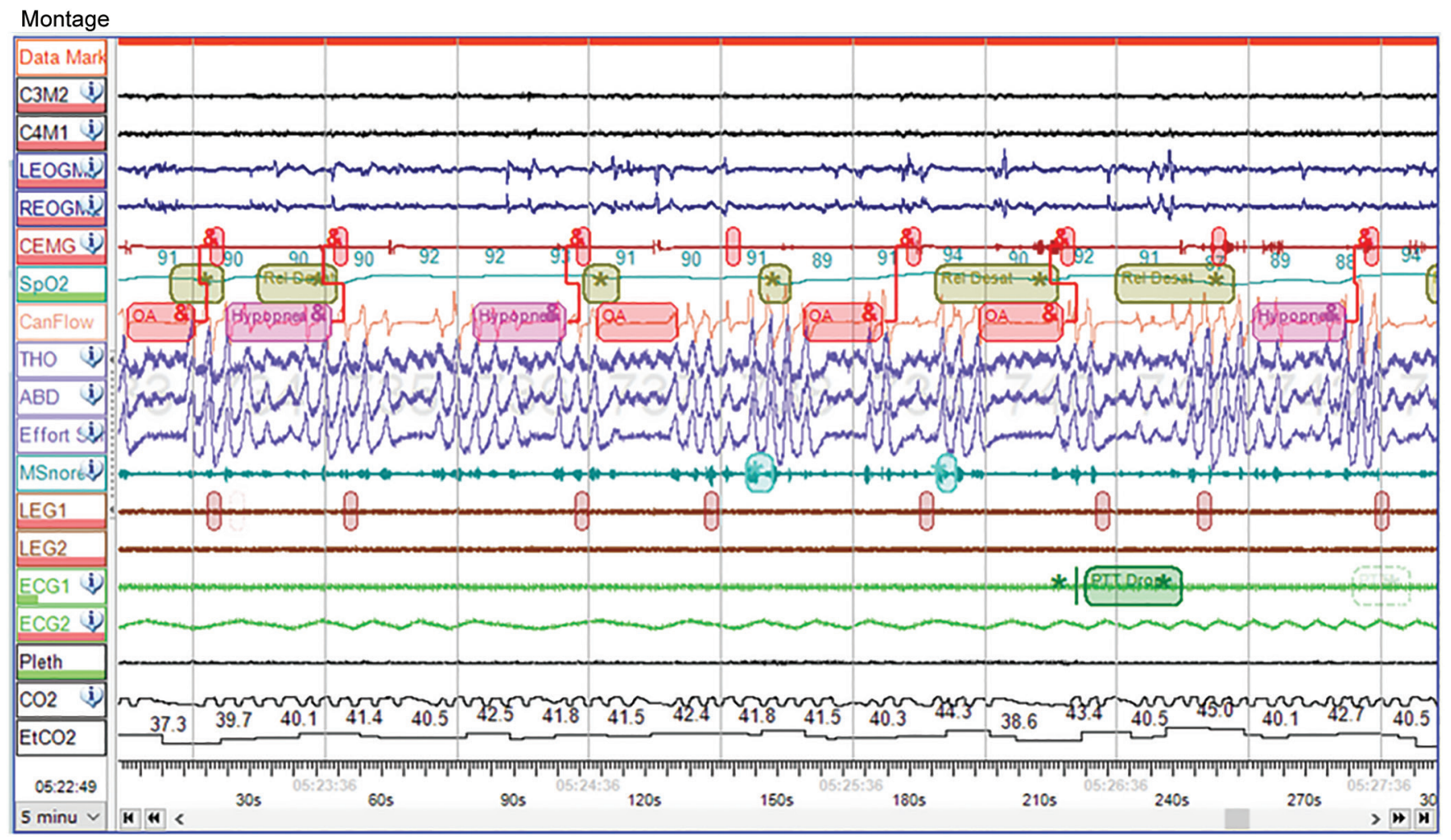

Fig. 2: Sleep study—Epoch of 5 minutes and montage 
Sleep Study Interpretation in Obstructive Sleep Apnea

Table 2: Parameters studied in PSG $^{3}$

\begin{tabular}{|c|c|c|}
\hline Variables & Channels used & Used for \\
\hline EEG & Electrodes placed over skull & Sleep onset and stages of sleep \\
\hline ECG & Electrodes over chest wall & Cardiac rhythms \\
\hline EOG & Electrodes around both the eyes & $\begin{array}{l}\text { Ocular movements for understanding sleep onset and } \\
\text { stage }\end{array}$ \\
\hline EMG & Electrodes over chin and anterior tibialis muscle & Sleep staging and limb movement disorders \\
\hline Respiratory movements & $\begin{array}{l}\text { Plethysmographic strain belts on chest and } \\
\text { abdomen }\end{array}$ & To distinguish central vs obstructive events \\
\hline $\mathrm{SPO}_{2}$ & Continuous pulse oximetry & Oxygen desaturation while sleep \\
\hline Respiratory efforts & $\begin{array}{l}\text { Oronasal thermistor or nasal pressure } \\
\text { transducers } \\
\text { Esophageal pressure, in selected patients }\end{array}$ & To see airflow limitation, detects apnea and hypopnea \\
\hline
\end{tabular}

\section{Variables in Sleep Study Report}

- Light-off time: The time at which patient falls to sleep. It is indicator of beginning of sleep data which is later analyzed on various aspects.

- $\quad$ Sleep latency: The time lag from the point lights are switched off until the patient enters into sleep confirmed by EEG and behavioral measures on the first epoch scored as sleep. In general, a sleep latency of more than 30 minutes is considered abnormal.

- $\quad$ REM latency: The time lag from the point lights are switched off until sleep study reveals first epoch with REM phase. Usually it is 90-120 minutes.

- Total recording time (TRT): The total duration from lights off to lights on.

- Total sleep time (TST): Amount of sleep recorded out of total recording time, i.e. sleep onset to sleep offset. This is in turn made up of N1, N2, N3 stages of NREM and REM phases, calculated in minutes.

- Sleep efficiency: The actual sleep time out of the total time one spends in bed is called sleep efficiency. It is calculated as sum of Stage N1, Stage N2, Stage N3, non rapid eye movement (NREM) and rapid eye movement (REM) divided by the total time in bed and multiplied by 100 . It defines how well the patient has slept. Normally, $80-89 \%$ is taken as acceptable cutoff for good sleep efficiency. ${ }^{4}$

- Wake after sleep onset (WASO): Duration of wakefulness after a defined onset of sleep. This depicts the fragmentation in sleep.

- Wake after sleep offset (WASF): Duration of wakefulness after a defined termination of sleep. Typically seen in elderly population where patients wake up after a short sleep time in early morning and find it difficult to reenter the sleep phase. It is an indicator of possible depression in patients as well.

- Carbon dioxide $\left(\mathrm{CO}_{2}\right)$ monitoring with transcutaneous $\mathrm{CO}_{2}$ $\left(\mathrm{PETCO}_{2}\right)$ or end tidal $\mathrm{CO} 2\left(\mathrm{ETCO}_{2}\right)$ : monitors carbon dioxide levels throughout the sleep study which is taken as a surrogate marker of partial pressure of $\mathrm{CO}_{2}$. Normal level of ETCO2 is $35-45 \mathrm{~mm}$ of $\mathrm{Hg}$. It is of use in pediatric polysomnography ${ }^{5}$ and those where hypoventilation is anticipated clinically.

- Arousal from sleep is an abrupt shift of EEG frequency including alpha, theta and/or frequencies greater than $16 \mathrm{~Hz}$ (but not spindles) that lasts at least 3 seconds, with at least 10 seconds of stable sleep preceding the change. Scoring of arousals in REM phase requires a concurrent increase in submental EEG for at least 1 second.

\section{Sleep Architecture}

Sleep is divided into rapid eye movement phase and nonrapid eye movement phase as described in Sleep and Health-An Introduction (Volume 10, Number 1). REM phase of sleep is very important in OSA patients which cycles every 90-120 minutes in sleep. We feel that if AHI calculated in REM phase is significant (i.e. more than total $\mathrm{AHI}$ ), severity of OSA should be escalated up for example from mild to moderate. Likewise, if sleep study shows an $\mathrm{AHI}$ of $<5 / \mathrm{hr}$ but $A \mathrm{HI}_{\mathrm{REM}}$ is $>5 / \mathrm{hr}$, then sleep study should be considered positive for OSA.

REM sleep is that phase of sleep where brain is as active as in awake state. REM sleep is essential for body functioning by helping in clearance of neurotoxins, consolidation of memory, emotional health and overall brain development. The feeling of refreshing sleep and recollection of your dreams signifies a sound REM sleep. Loss of REM sleep is a concerning state which can happen due to sleep deprivation, due to frequent interruptions like in untreated OSA patients. Additionally, patients who are on antidepressant drugs or benzodiazepine also face an issue of reduced REM phase sleep. When CPAP is initiated in patients with OSA especially with severe grades, the loss in REM due to disease is compensated in form of increase in frequency ( 6 to $20 \%$ ) and depth of REM phases called as REM rebound. ${ }^{6}$ REM phase behavioural disorder (RBD) is a form of parasomnia which is characterized by loss of normal skeletal muscle atonia which is usually associated with REM sleep leading to prominent motor activity allowing the person to "act out" his or her dreams. ${ }^{7}$ Patients with narcolepsy, like patients with RBD, present a higher percentage of REM sleep without atonia. Depression is also known to cause REM sleep dysregulation.

\section{Events in Sleep Study Report}

\section{Respiratory Events ${ }^{8}$}

- Apnea:Drop in peak signal excursion in oronasal thermal sensor (or alternative) by $\geq 90 \%$ of baseline for a duration $\geq 10 \mathrm{sec}$ and at least $90 \%$ of event duration must meet apnoea amplitude reduction criteria. Importantly, desaturation is not needed to score an apnoea.

There are different types of apnoea events as per accompaniments:

- Obstructive: continued or increased inspiratory effort for the duration of apnea

- Central: Absent inspiratory effort for the duration of apnea 
- Mixed: Initially absent inspiratory effort in the first portion of the event and then resumption of inspiratory effort during second portion of event

- Hypopnea: Nasal pressure (NP) excursions (or alternative sensor) drop by $\geq 30 \%$ of baseline amplitude for a duration $\geq 10$ sec and at least $90 \%$ of duration meets hypopnea amplitude criteria. This should be associated with $\geq 4 \%$ arterial oxygen desaturation from pre-event baseline. Alternatively, NP excursions (or alternative sensor) drop by $\geq 50 \%$ of baseline amplitude for duration $\geq 10 \mathrm{sec}$ and at least $90 \%$ of duration meets hypopnea amplitude criteria. This should be associated with $\geq 3 \%$ arterial oxygen desaturation from pre-event baseline or an arousal. ${ }^{9}$

- Respiratory Effort-related Arousals (RERAs): A sequence of breaths lasting at least $10 \mathrm{sec}$ with increasing respiratory effort or flattening of the nasal pressure waveform followed by an arousal from sleep. These events fail to meet the criteria for an apnea or hypopnea.

- Hypoventilation: Increase in $\mathrm{PaCO}_{2}$ or validated surrogate $\geq 10$ $\mathrm{mm} \mathrm{Hg}$ above the supine awake value.

\section{Cardiac Events}

Tachybradyarrhymias can happen while sleep. One should look for rhythm disorders carefully (refer to upcoming Issue 3: Sleepdisordered Breathing and Cardiac Disorders). If chest pain or profuse perspiration is noted, one should look for ECG changes to detect nocturnal angina.

\section{Oxygen Saturation $\left(\mathrm{SpO}_{2}\right)$}

$\mathrm{SpO}_{2}$ monitoring is a very important component of sleep apnea testing. Usually, significant desaturation is defined as decrease in $\mathrm{SpO}_{2}$ by $3-4 \%$ or more from the baseline value. Importantly, lowest value of $\mathrm{SpO}_{2}$ commonly follows apnea (hypopnea) termination by approximately $6-8$ seconds. This delay is attributable to circulation time and instrumental technique. Lowest $\mathrm{SpO}_{2}$ should be seen to understand the extent of compromise due to OSA. However duration of hypoxemia is equally important as the extent of desaturation. Desaturation index is defined as hourly average number of desaturation episodes.

\section{Leg Movements}

Periodic limb movement index (PLM index) should be seen for both the legs. More than 4 consecutive periodic limb movements should be there to be considered as an event. More than $15 \mathrm{PLMs} /$ hour is significant. If PLMs are associated with arousal, it becomes even more significant. PLMs can be easily distinguished from restless leg syndrome where patient is more symptomatic in awakened state.

\section{Body Position}

Usually lying on back (supine position) compromises airway more than any of the lateral decubitus positions. If in a particular position number of apnea or hypopneas are noted more in number, then it should be documented separately as positional therapies can be helpful in such patients in addition to PAP therapy. PAP titration should also be carefully done seeing that all the body positions are covered.

\section{Arousal Index}

Arousal index was defined as the total number of arousals in sleep, divided by the total sleep time. Normal range is $9-16$. With age arousal index increases. It demarcates fragmentation of sleep leading to nonrestorative sleep. ${ }^{10}$

\section{Grading of Disease}

Disease like OSA or CSA is graded as per AHI value on PSG results as described in obstructive sleep apnea. Duration of apnea event also holds significance in grading the severity. If a patient has relatively lesser AHI but individual events are prolonged or having a severe drop in oxygen levels, it should be taken into account.

\section{CPAP Titration Study}

Once diagnosed with OSA, next step should always be a CPAP titration study. Once the patient enters into sleep, CPAP is applied with minimum pressures, usually $4 \mathrm{~cm}$ of $\mathrm{H}_{2} \mathrm{O}$ to begin with. Gradually, pressures are increased by a trained sleep technician to reach a pressure value where all the respiratory events are abolished. Thereafter, optimum pressures are declared and documented. Titration should be done in both REM and NREM sleep and in all body positions. Target is not only a reduced $\mathrm{AHI}$ or improved oxygen levels but also quality of sleep. If at a pressure level, patient develops arousals or central events then the pressures are lowered down to reach an optimum state. Manual titration is superior to autotitration if a well-read technician is available. Typically, 95th percentile or 90th percentile pressure (depending upon the device) is used as the prescribed pressure for CPAP on long-term basis. 95th percentile pressure means that 95\%-time patient was at or below that pressure. If patient is hypoxic at the beginning of the study, oxygen should be continued while titration study as well. If titration with CPAP seems to be difficult especially in overtly obese patients or those with overlap syndromes, titration with bi-level mode should be opted for.

\section{Primary Snoring}

Snoring may be defined as a vibratory, sonorous noise made during inspiration and, less commonly, expiration due to vibration (fluttering) of the soft palate and other pharyngeal structures. Simple or primary snoring is defined as the presence of snoring in absence of insomnia, daytime sleepiness, or sleep fragmentation. PSG shows evidence of snoring without significant number of apneas, hypopneas or RERAs. Sleep architecture is usually well preserved. Snoring has been identified as a cardiovascular risk thus needs to be addressed. Primary snorers should be managed in a similar way as mild OSA patients with weight loss, side sleep position, treatment of nasal congestion, upper airway surgery, an oral appliance and avoidance of alcohol. The surgical procedures commonly used for snoring include laser-assisted uvulo palatoplasty (LAUP), radiofrequency palatoplasty, and uvulopalatopharyngoplasty (UPPP). ${ }^{11}$ Oral appliances can be used in primary snorers, who do not respond or are not appropriate candidates for treatment with initial effective measures such as weight loss or sleep position change.

\section{Pearls of Wisdom}

- Prior to sleep study a comprehensive sleep history and examination clearly mentioning the indication for sleep study should be ensured

- Level 1 study is the gold standard in evaluation of sleep disordered breathing

- Comments from sleep technician and their assessment notes should be taken in to consideration while reporting the study 
- Grading of OSA/CSA is done on basis of AHI/RDI values as mild, moderate and severe. Extent of desaturation, duration of apnea episode and REM events should also be given due importance

- Other forms of SDB should also be looked for along with OSA as per the clinical setting

- Once diagnosed with OSA/CSA, CPAP titration is equally important for management.

\section{References}

1. Kapur VK, Auckley DH, et al. Clinical practice guideline for diagnostic testing for adult obstructive sleep apnea: an American Academy of Sleep Medicine clinical practice guideline. J Clin Sleep Med. 2017;13(3):479-504.

2. Collop NA, Anderson WM, et al.; for the Portable Monitoring Task Force of the American Academy of Sleep Medicine. Clinical guidelines for the use of unattended portable monitors in the diagnosis of obstructive sleep apnea in adult patients. J Clin Sleep Med. 2007;3(7):737-747.

3. Berry RB, Brooks R, et al.; for the American Academy of Sleep Medicine. The AASM Manual for the Scoring of Sleep and Associated Events: Rules, Terminology and Technical Specifications. Version 2.3. Darien, IL: American Academy of Sleep Medicine; 2016.
4. Ref: Ohayon MM, Carskadon MA, et al. Meta-analysis of quantitative sleep parameters from childhood to old age in healthy individuals: developing normative sleep values across the human lifespan. Sleep 2004;27:1255-1273.

5. Beck SE, Marcus CL. Pediatric Polysomnography. Sleep medicine clinics. 2009;4(3):393-406. doi:10.1016/j.jsmc.2009.04.007

6. Nigam. Rapid Eye Movement(REM) rebound on initial exposure to CPAP therspy: a systematic review and meta analysis.Sleep Science Practice (2017) 1:13

7. Schenck C, Mahowald M. REM sleep behavior disorder: clinical, developmental, and neuroscience perspectives 16 years after its formal identification in SLEEP. Sleep. 2002;25:120-138.

8. Iber C, Ancoli-Israel S, et al. for the American Academy of Sleep Medicine: The AASM Manual for the Scoring of Sleep and Associated Events: Rules, Terminology and Technical Specifications, 1st ed. Westchester, IL: American Academy of Sleep Medicine, 2007.

9. Iber C, Ancoli-Israel S, et al. for the American Academy of Sleep Medicine: The AASM Manual for the Scoring of Sleep and Associated Events: Rules, Terminology and Technical Specifications, 1st ed. Westchester, IL: American Academy of Sleep Medicine, 2007.

10. Bonnet M, Arand DL. EEG arousal norms by age. J Clin Sleep Med 2007;3:271-274.

11. Caples SM, Rowley JA, et al. Surgical modifications of the upper airway for obstructive sleep apnea in adults: a systematic review and metaanalysis. Sleep 2010;33:1396-1407. 